\title{
TOTAL FLAVONOID QUANTIFICATION AND TO STUDY ANTIBACTERIAL POTENCY OF EXTRACTS OF BUTEA MONOSPERMA FLOWERS, NIGELLA SATIVA SEEDS AND VITEX AGNUS CASTUS LEAVES
}

\author{
KAJAL L. JAIN*, P. K. CHOUDHURY, MAYA SHARMA \\ Department of Pharmaceutical Sciences, New Campus, Mohanlal Sukhadia University, Udaipur 313001(Rajasthan), India \\ Email: kajaljain@hotmail.com
}

Received: 27 Dec 2016, Revised and Accepted: 20 Mar 2017

\begin{abstract}
Objective: An attempt has been made to develop a method for quantitative estimation of flavonoids in the crude extract of Butea monosperma flowers, Nigella sativa seeds and Vitex agnus castus leaves. Antibacterial activity is attributed to various phytochemicals present in these plants.

Methods: The amount of total flavonoids was analysed using aluminium chloride colorimetric assay using rutin as standard. Plants studied were subjected to hydromethanolic extraction by using soxhlet apparatus. Flavonoids in extracts were quantified by U. V at a wavelength of 415 nm Antibacterial activities of extracts were evaluated on various bacterias like E. coli, P. aeruginosa, S. aureus, S. pneumonie, P. acne. The in vitro antibacterial activities of these extracts were compared against standard drugs such as gentamycin, ampicillin, chloramphenicol, ciprofloxacin, norfloxacin.
\end{abstract}

Results: Flavonoid content in the crude extract of Butea monosperma flowers, Nigella sativa seeds and Vitex agnus castus leaves was found to be $2.58 \% \mathrm{w} / \mathrm{w}, 0.92 \% \mathrm{w} / \mathrm{w}$ and $1.6 \% \mathrm{w} / \mathrm{w}$ respectively. The antibacterial study found that activity of Vitex extract against $P$. acne was better than the standard drugs

Conclusion: In the present study an attempt has been made to standardize the plant material in terms of its flavonoid content and the study indicated that this extract individually or in combination with other herbal drugs can be useful in treating diseases caused by the organisms mentioned above.

Keywords: B. monosperma, N. sativa, V. agnus-castus, Hydroalcoholic extract, Rutin

(C) 2016 The Authors. Published by Innovare Academic Sciences Pvt Ltd. This is an open access article under the CC BY license (http://creativecommons.org/licenses/by/4.0/) DOI: http://dx.doi.org/10.22159/ijcpr.2017v9i3.18901

\section{INTRODUCTION}

The Ayurvedic system of medicine is prevalent in India, since the vedic period and as early as the dawn of human civilization. There has been a tremendous increase in the usage of traditional and herbal medicines in the past few years. Population living in the developing countries relies almost exclusively on traditional medicine for their primary healthcare needs. Plants contain various phytochemicals including secondary metabolites and antioxidants. Antioxidants are very essential in today's stressed life. Moreover, resistance to antibiotics has also resulted in increased usage of herbal drugs.

Many drugs of plant origin have potential to treat various human ailments. Butea monosperma belonging to family Fabaceae and popularly known as 'palas', 'Flame of forest' [1]. This is a moderate sized deciduous tree widely distributed throughout India, Burma and Ceylon extending in the north-west Himalayas as far as Jhelum except in very arid regions [2,3]. The plant contains flavonoids and glucosides butin, butrin, isobutrin and palastrin. Flowers contain butrin, coreopsin, monosperm onside and their derivatives and sulphurein; also chalcones. The bark is used as astringent, styptic (prescribed in bleeding piles, ulcers, haemorrhages, and menstrual disorders), anthelmintic. Flowers are used as astringent, diuretic, emmenagogue (also given for leucorrhoea) [4].

Nigella sativa is also named as English cumin, kalonji, pyaz ke beej [3]. It consists of seeds of Nigella sativa Linn. belonging to family Ranunculaceae. The plant is a small herb, $45-60 \mathrm{~cm}$ high, mostly cultivated in Punjab, Himachal Pradesh, Bihar and Assam [5]. Seeds are stimulant, carminative, diuretic, lactiferous, emmenagogue (stimulate uterine contractions), also used in puerperal fever. Powdered seeds externally applied to boils. Essential oil is used in common cold, cough and bronchospasm. The essential oil from seeds contains nigellone and methyl isopropyl-pquinone. The oil contains carvone, d-limonene and cymene. The ethanolic extract of the seeds and the volatile oil from seeds showed antispasmodic activity in experimental animals, possibly due to a calcium antagonistic effect. The oil exhibited CNS depressant and potent analgesic effects on experimental animals, possibly due to the presence of an opioid principle in the oil [3]. The seeds possess well marked carminative and stomachic properties and are used in combination with other aromatic substances and bitters. It is also used in eczema [2].

Vitex leaves consist of dried leaf of Vitex agnus castus Linn. of family Verbenaceae. It is a large aromatic shrub or a small tree, up to $4.5 \mathrm{~m}$ in height, common throughout the country ascending to an altitude of $1500 \mathrm{~m}$ in the outer Himalayas. It is common in waste places around villages, river banks, and moist localities and in the deciduous forests [5]. In Ayurvedic medicine Leaf is used as antiinflammatory, analgesic; removes foetid discharges and worms from ulcers. The Ayurvedic Pharmacopoeia of India recommends the leaf (also the root) in excessive vaginal discharges, oedema, skin diseases, pruritus, helminthiasis, rheumatism, and puerperal fever [3].

\section{MATERIALS AND METHODS}

\section{Procurement of plant material}

Butea monosperma Lam. flowers and Nigella sativa Linn. seeds were collected from local region of Udaipur, Rajasthan, India and Vitex agnus castus were procured from 5 P's Cocopeat and organic Products, Coimbatore, Tamilnadu, India and authenticated by Botany section, Vindhya herbal testing laboratory, Minor Forest Produce Processing and Research centre-MFP-PARC, Bhopal, M. P and voucher samples are deposited there for further reference.

\section{Preparation of plant extract}

Butea. monosperma Lam. flowers and Vitex agnus castus leaves were air dried, then crushed and was extracted with hydroalcohol (water: methanol, 50:50) in soxhlet apparatus. Nigella sativa Linn. seeds 
were examined for the presence of foreign matter, then crushed and extracted with hydroalcohol (water: methanol, 50:50) in soxhlet apparatus. The extracts were filtered, concentrated and finally evaporated in a rotary evaporator to dry powder form and kept in the refrigerator for further studies.

\section{Reagents}

Rutin was obtained from Sigma-Aldrich, Mumbai. Methanol used was of HPLC grade. Chemicals used in analysis like phosphoric acid, aluminium chloride and potassium acetate were of analytical grade.

\section{Preparation of standard solution}

A stock rutin standard solution of $1 \mathrm{mg} / \mathrm{ml}$ was prepared by dissolving rutin reference material in $80 \%$ methanol. From this stock solution, various solution ranging from concentration 1-50 $\mu \mathrm{g} / \mathrm{ml}$ were prepared for obtaining a calibration curve.

\section{Sample preparation for UV spectrophotometry}

The herbal extract $(1 \mathrm{mg} / \mathrm{ml})$ was prepared by dissolving it in $80 \%$ methanol. It was then further diluted to obtain absorbance lesser than 1 in UV spectrophotometry.

\section{Selection of the detection wavelength}

The 200-800 nm absorption spectra of the standard and sample solution extraction complexed with aluminium chloride were obtained. Both of them had maximum absorption $\left(\lambda_{\max }\right)$ at $415 \mathrm{~nm}$ which was then chosen as the detection wavelength.

\section{Procedure for the determination of total flavonoids $[6,7]$}

The total flavonoid in the crude extracts was measured using the Aluminium chloride colorimetric method. To $0.5 \mathrm{ml}$ of the standard of different concentrations and plant extract, $1.5 \mathrm{ml}$ of $80 \%$ methanol, $0.1 \mathrm{ml}$ potassium acetate $(1 \mathrm{M})$ and $0.1 \mathrm{ml}$ of $10 \%$ aluminium chloride was added. Distilled water was then added to make volume up to $5 \mathrm{ml}$. Then the solution was incubated for $30 \mathrm{~min}$ at room temperature. The absorbance was measured at $\lambda_{\max } 415 \mathrm{~nm}$ using UV spectrophotometer against a blank. A standard curve was prepared by dissolving rutin in methanol followed by serial dilution. The result was expressed in percentage of total flavonoid content, calculated as rutin.

\section{Antibacterial potency-minimum inhibitory concentration (MIC) [8]}

The lowest concentration of an antimicrobial agent (in $\mathrm{mg} / \mathrm{l}$ ) that prevents the appearance of visible growth of a microorganism within a defined period of time is known as the MIC. Appropriate stock solutions for the said herbal extracts namely Butea monosperma, Vitex agnus-castus and Nigella sativa were labelled as $\mathrm{B}, \mathrm{V}$ and $\mathrm{N}$ respectively. The stock solutions were diluted in sterile distilled water to make appropriate test concentrations as required.

In vitro susceptibility tests like MIC are performed on microorganisms suspected of causing disease, particularly if the organism is thought to belong to a species that may exhibit resistance to frequently used antimicrobial agents. Dilution methods are used to determine the MIC of antimicrobial agents and are the reference methods for antimicrobial susceptibility testing. MIC methods are used for discovery of novel antimicrobial drugs or resistance surveillance, the comparative testing of new agents, to establish the susceptibility of organisms that give equivocal results in disc tests, for tests on organisms where disc tests may be unreliable and when a quantitative result is required for clinical management.

MIC was performed using broth dilution method. Broth dilution is a technique in which containers holding identical volumes of broth with an antimicrobial solution in incrementally (usually geometrically) increasing concentrations are inoculated with a known number of bacteria. Final organism density of $5 \times 10^{5} \mathrm{cfu} / \mathrm{ml}$ was adjusted.

\section{RESULTS AND DISCUSSION}

The extract contains various constituents in it and here the flavonoid concentration is measured taking rutin flavonoid as standard. The total flavonoid in the crude extracts was measured using the Aluminium chloride colorimetric method. A standard curve was prepared using rutin as the standard by dissolving it in methanol followed by serial dilution. Absorbance is measured for the concentration range of $1-50 \mu \mathrm{g} / \mathrm{ml}$ and plotting these values in graph gave a straight line with a slope of 0.017 and y-intercept of 0.003 . The equation of line being $y=0.017 x+0.003$. It was run in triplicate to determine the amount of flavonoids in these plants.

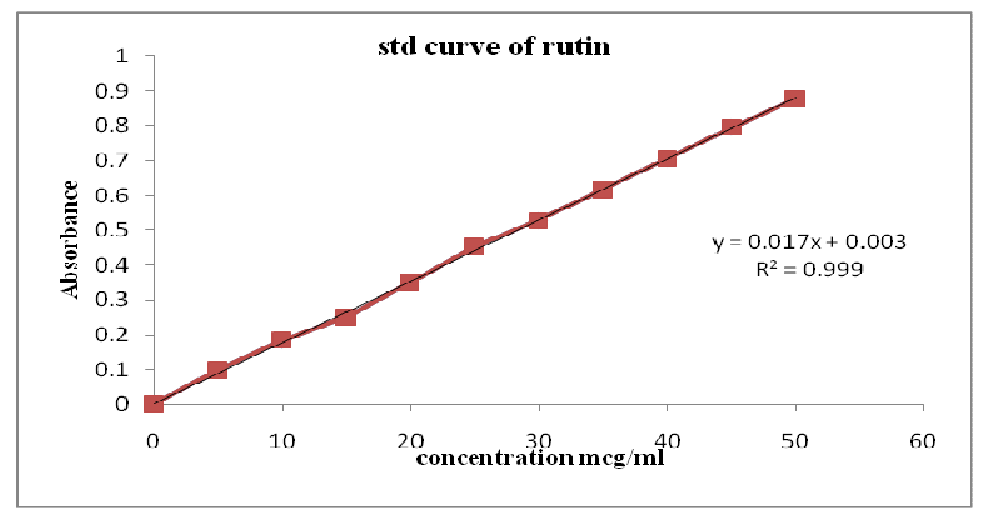

Fig. 1: Std curve of rutin

Drug extracts were also diluted and then samples were prepared as per procedure and absorbance was read at $\lambda \max -415 \mathrm{~nm}$. Flavonoid concentration in these extracts was then calculated from the regression equation.

Table 1: Flavonoid content (\%) in various plant parts

\begin{tabular}{ll}
\hline Drug & Flavonoid content $(\% \mathbf{w} / \mathbf{w})$ \\
\hline Butea monosperma & $2.576 \pm 0.035$ \\
Nigella sativa & $0.921 \pm 0.029$ \\
Vitex agnus-castus & $1.592 \pm 0.0295$ \\
\hline
\end{tabular}

\section{Validation of the UV method}

The linearity of the method was performed by analyzing a standard solution of rutin by the proposed method in the concentration range of $1-50 \mu \mathrm{g} / \mathrm{ml}$. Mean of three readings were used to prepare a standard curve. Regression line equation is $y=0.017 x+0.003$ which is then further used for calculation of limit of detection and quantification. The slope of the equation is 0.017 and $y$-intercept is 0.003 .

The accuracy of the proposed method was determined by recovery study. Recovery study was carried out by adding different quantities 
of rutin to the pre-analyzed solution of extract. All the procedure was repeated thrice. From the linear regression percentage recovery of rutin were determined. From the colorimetric method of flavonoid analysis, the amount of flavonoid in these plants was found. To this solution amount of standard rutin solution of varied concentration were added such that it is $100 \%$ of flavonoid present in the extract. Results are mentioned in table 2 as below.
Precision was determined by repeatability, intraday and interday reproducibility experiment of the proposed method. The intraday reproducibility was determined by analyzing freshly prepared solution in triplicate at three different times in the same day whereas inter-day reproducibility was checked by analyzing the standard solutions at three different days under same operative condition.

Table 2: \% recovery study

\begin{tabular}{lll}
\hline S. No: & Amount of flavonoid in plant extract $(\boldsymbol{\mu g})$ & Amount of standard rutin added $(\boldsymbol{\mu g})$ \\
\hline 1 & 12.88 & 15 \\
2 & 12.88 & 15 \\
3 & 12.88 & 15 \\
4 & 4.59 & 5 \\
5 & 4.59 & 5 \\
6 & 4.59 & 5 \\
7 & 7.94 & 8 \\
8 & 7.94 & 8 \\
9 & 7.94 & 8 \\
\hline
\end{tabular}

Table 3: Inter-day and Intraday precision study $(n=3)$

\begin{tabular}{lll}
\hline Concentration of rutin $(\boldsymbol{\mu g})$ & mean \pm std deviation \\
\cline { 2 - 3 } & Inter-day precision & \multicolumn{1}{c}{ Intraday precision } \\
\hline 5 & $0.098 \pm 0.009$ & $0.091 \pm 0.034$ \\
10 & $0.185 \pm 0.011$ & $0.181 \pm 0.008$ \\
15 & $0.25 \pm 0.027$ & $0.232 \pm 0.02$ \\
20 & $0.351 \pm 0.028$ & $0.334 \pm 0.013$ \\
25 & $0.452 \pm 0.028$ & $0.436 \pm 0.012$ \\
30 & $0.527 \pm 0.004$ & $0.518 \pm 0.006$ \\
35 & $0.617 \pm 0.021$ & $0.605 \pm 0.012$ \\
40 & $0.704 \pm 0.035$ & $0.691 \pm 0.028$ \\
45 & $0.795 \pm 0.018$ & $0.772 \pm 0.006$ \\
50 & $0.876 \pm 0.021$ & $0.861 \pm 0.004$ \\
\hline
\end{tabular}

Limit of Detection of rutin was found to be $1.75 \mu \mathrm{g}$ and Limit of Quantification was found to be $5.29 \mu \mathrm{g}$.

Minimal Inhibition Concentration (MIC) of all drugs is different for every microbial strain. Any particular drug may be more effective against some bacteria and may not be effective at all for some strain.
Comparison of all three extracts against five different bacterial strains is presented here in table No: 4. Different standards have been compared along with test extract against these bacteria.

The activity of Vitex agnus castus leaves against P. acne is comparable to that of standard Norfloxacin drug.

Table 4: Minimum inhibition concentration of std drugs and test plant drugs

\begin{tabular}{|c|c|c|c|c|c|c|}
\hline \multicolumn{7}{|c|}{ Minimal inhibition concentration $\mu \mathrm{g} / \mathrm{ml}$} \\
\hline \multirow[t]{2}{*}{ S. No. } & \multirow{2}{*}{$\begin{array}{l}\text { Code no: } \\
\text { Test sample }\end{array}$} & \multicolumn{5}{|c|}{ test and standard concentration in $\mu \mathrm{g} / \mathrm{ml}$} \\
\hline & & E. coli & P. aeruginosa & S. aureus & S. pneumonie & P. acne \\
\hline 1 & B. monosperma extract & 250 & 200 & 250 & 200 & 100 \\
\hline 2 & Nigella sativa extract & 250 & 100 & 62.5 & 250 & 250 \\
\hline 3 & Vitex agnus-castus extract & 125 & 250 & 125 & 25 & 12.5 \\
\hline \multicolumn{7}{|c|}{ Standard samples } \\
\hline 1 & Gentamycin & 0.05 & 1 & 0.25 & 1 & 0.25 \\
\hline 2 & Ampicillin & 100 & - & 250 & 250 & 100 \\
\hline 3 & Chloramphenicol & 50 & 50 & 50 & 50 & 25 \\
\hline 4 & Ciprofloxacin & 25 & 25 & 50 & 50 & 50 \\
\hline 5 & Norfloxacin & 10 & 10 & 10 & 100 & 10 \\
\hline
\end{tabular}

\section{CONCLUSION}

One can use this validated method for flavonoid analysis and it can be used as a standardization tool for the plant analysis. Many microbes are becoming resistant to presently available antibiotics; hence drugs from other sources need to be found. In the present study antibacterial effect of plant Butea monosperma, Nigella sativa and Vitex agnus castus against various bacteria have been carried out by broth dilution method. The study indicates that this extract individually or in combination with other herbal drugs can be useful in treating diseases caused by these organisms mentioned above. Antibacterial activity against $P$. acne was more compared to other bacteria, which suggests its use as antibacterial/preservative in skin formulation. Current study scientifically validates the use of the plant as an antimicrobial agent and anti-acne agent.

\section{ACKNOWLEDGMENT}

The facilities provided by the Department of Pharmaceutical Sciences, Mohanlal Sukhadia University is gratefully acknowledged.

\section{CONFLICT OF INTERESTS}

Declare none 


\section{REFERENCES}

1. Kirtikar KR, Basu BD. Indian medicinal plants. $2^{\text {nd }}$ edition. Vol. I. Lalit Mohan Basu Allahabad, India; 1935. p. 785-8.

2. Chopra RN, Chopra IC, Handa KL, Kapur LD. Indigenous drugs of India. $1^{\text {st }}$ edition. Bimal Kumar Dhur; 1958. p. 301$3,680$.

3. CP Khare. Indian medicinal plants. Springer science and business media; 2007. p. 105-6, 439, 709-10.

4. The Wealth of India-raw materials. Vol. II(B), PID, CSIR, New Delhi; 1988. p. 341-6.

5. Ayurvedic Pharmacopoeia of India. Part 1. Vol. 3. Government of India, Ministry of health and family welfare, Department of AYUSH; 2006. p. 143-5.
6. Milan S, Stanković. Total phenolic content, flavonoid concentration and antioxidant activity of marrubium peregrinum extracts. Kragujevac J Sci 2011;33:63-72.

7. Maheshkumar S Kale, Kirti S Laddha. Determination of total flavonoids content and quantification of rutin in Momordica tuberose (Roxb) Cogn. fruits by RP-HPLC. Asian J Tradit Med 2012;7 Suppl 5:220-5.

8. Andrews JM. Determination of minimum inhibitory concentrations. J Animicrobial Chemother 2001;48 Suppl 1:5-16.

\section{How to cite this article}

- Kajal L Jain, PK Choudhury, Maya Sharma. Total flavonoid quantification and to study antibacterial potency of extracts of butea monosperma flowers, nigella sativa seeds and vitex agnus castus leaves. Int J Curr Pharm Res 2017;9(3):71-74. 